\title{
Interferencia italiana en el español renacentista y áureo. Las formas de tratamiento
}

Palabras clave: interferencia, préstamo, calco, italiano, español, fórmulas de tratamiento

\section{Introducción}

El contacto entre lenguas es una de las principales causas del cambio lingüístico, dado que a través de diversos mecanismos, un determinado código se enriquece con nuevos elementos que se integran (préstamos) o se adaptan (calcos) según las necesidades intrínsecas y comunicativas del momento. Gracias a ellos la lengua receptora puede disponer - a veces de manera pasajera - de unidades más claras, más transparentes y mejor adaptadas a la constante evolución de la sociedad.

Ante las múltiples definiciones - algunas contradictorias- que abarcan los términos de préstamo y calco, en este estudio vamos a entender por préstamo el resultado de un proceso sincrónico o diacrónico de asimilación total o parcial de un elemento de la lengua fuente en la lengua receptora, y por calco la adaptación de una estructura ajena que utiliza elementos de la lengua receptora (vid. Weinreich, 1963; Sala, 1998).

Las causas de las interferencias entre lenguas son, evidentemente, múltiples, dado que entran en juego factores tanto extralingüísticos (intensidad del contacto, moda, prestigio de la lengua meta, etc.) como lingüísticos (término más apropiado, estructura más clara, insuficiencia del sistema de la lengua receptora, etc.) (Thomason, 2001: 60-61).

Sin lugar a dudas, la intensidad del contacto no es una condición sine qua non, pero fomenta incuestionablemente la transferencia lingüística de un código 
al otro. Esta, por lo general, comienza a producirse en el nivel léxico y, si se prolonga, puede extenderse a otros niveles de lengua siempre que no implique desajustes en sus propias tendencias evolutivas (Weinreich, 1963: 7-10), de ahí que resulte lógico suponer que entre dos lenguas en contacto tipológicamente idénticas y pertenecientes a la misma familia se produzcan interferencias más fuertes que entre lenguas no emparentadas ni tipológica ni genéricamente (Thomason, 2001: 60; 2003: 691-93).

Sirvan como ejemplo de lenguas en contacto el italiano y el español a lo largo del Renacimiento y del Siglo de Oro, tema objeto del presente estudio. A partir de 1420 las relaciones políticas, culturales y militares entre Italia y España se intensifican de manera inusitada. Es precisamente por aquella época cuando muchos españoles pasan por Italia y, al volver a España, llevan consigo términos alusivos a la vida social, cultural, militar o comercial que conocemos como italianismos, vocablos y expresiones que remiten a varias modalidades lingüísticas de la península itálica. A este contacto directo hay que sumar el indirecto: lecturas de obras literarias y de otros tipos que tanto influyeron en el español de aquellos tiempos y siguen presentes en el contemporáneo, como prueba la presencia de 608 voces de este origen que recoge la RAE (Ayala Simón, 2002:39), lo cual pone en evidencia que el italiano constituye una de las principales fuentes léxicas extranjeras de la lengua española, junto al latín, al árabe y al francés.

El prestigio del que gozó el italiano en las etapas renacentista y clásica no solo provocó una notable integración de préstamos léxicos en español, bastante bien estudiados (vid. Terlingen, 1943; Dworkin, 2012), sino que también supuso la adaptación de costumbres lingüísticas corteses, entre las cuales se encuentran fórmulas de tratamiento no registradas con anterioridad, hecho nada sorprendente, ya que no puede ser calificada de casual la publicación en Italia del primer savoir-vivre de la Europa de entonces, cuyas ideas sobre lo cortés abonaron satisfactoriamente el terreno español, de marcado gusto por el ritual y la ceremonia (Lapesa, 1970: 146; Líbano Zumalacárregui, 1991:116; Hernández Alonso, 1996: 97, entre otros). De hecho, su autor, Baltasar de Castiglione, aporta una contundente opinión sobre los españoles (1a), cuya afición por lo ceremonioso queda reflejada en las fórmulas de tratamiento ( $1 \mathrm{~b}$ ).

En virtud de ello, si nos detenemos en las formas del español renacentista, vemos un notable incremento de expresiones alocutivas antes no registradas, entre las que se encuentran vuestra señoría (> usía) (1c), vuestra excelencia (> vuesencia) (1d) y una serie con sufijo superlativo (1e). 
(1) a. Hispanos etiam intuere, qui verae curialitatis magistri videri volunt (Castiglione, Il Cortegiano,1528, apud Svennung 1958: 95)

['los españoles pretenden ser vistos como verdaderos maestros de cortesía']

b. No se puede hablar al más humilde del populacho sin bostezarle todos los títulos de honor, y entre ellos se tratan de señores caballeros (Antoine de Brunel, Voyage d'Espagne curieux, bistorique et politique. Fait en l'année 1655, apud Díez Borque 1990: 119).

c. Señor, desque seamos dentro en la cámara, si el caso lo requiere, ¿qué es lo que vuestra señoría manda que fagamos? (Anónimo, Crónica de Don Álvaro de Luna, ca. 1453)

d. ca no me hallo tan loco que no sé que sé tan poco que no toco al pie de vuestra excelencia (Pulgar Hernando, Letras, ca. 1470-1485)

e. Serenissimo rey, nuestro muy caro e muy amado sobrino (Anónimo, Fernando al rey Fernando de Nápoles, 1495)

Este panorama nos lleva a plantear la hipótesis de que su repentino florecimiento se debe a interferencias pragmáticas del italiano. A lo largo de las páginas siguientes trataremos de defenderla y justificarla aplicando una aproximación basada en el uso (ingl. based usage approacb) con ayuda de dos corpus electrónicos: el CORDE para los textos españoles y el OVI para los italianos. Nuestro planteamiento se basa en la aseveración de Jucker y Taavitsainen (2003: 2-3) de que las formas de tratamiento son muy susceptibles a las interferencias entre lenguas.

La estructura de este trabajo es la siguiente: aparte de esta introducción y de las conclusiones expuestas al final, hemos considerado dividir el estudio en dos apartados. En el primero presentamos sucintamente el contexto sociohistórico, indispensable para abordar el estudio lingüístico, y en el segundo nos centramos en las fórmulas de tratamiento.

\section{Contexto sociohistórico}

Durante el Medievo las relaciones entre España e Italia eran esporádicas (Terlingen, 1943: 43-45), lo cual, desde una perspectiva lingüística, puede explicar la introducción - a veces indirecta - de algunos italianismos léxicos (belleza < it. belle$z a$; terremoto < it. terremoto; capucho < it. cappuccio), cuyo origen no siempre resulta 
claro (Dworkin, 2012: 142-144). A partir de la segunda mitad del siglo XIII, con la creación por el cardenal Gil de Albornoz del Colegio de San Clemente - hoy conocido como Real Colegio de España - en la Universidad de Bolonia, el interés por la cultura italiana sensu lato se vuelve visible en la península ibérica ${ }^{1}$.

Las relaciones bilaterales se intensificaron a partir de 1443 con la conquista de Nápoles por Alfonso V de Aragón. Allí se forma un núcleo de poder, primero, aragonés y, luego, castellano que requiere un constante contacto con la corona. Cuatro lustros más tarde, el cardenal valenciano Alfons de Borja se convierte en papa con el nombre de Calixto III y se forma otro importante núcleo español en Roma, que da lugar a una rica correspondencia diplomática. Con la paz de Cateau-Cambrésis, firmada en 1559 entre Felipe II y Enrique II de Francia, España confirmó su hegemonía en casi toda la península itálica.

Todo ello fue la causa, por una parte, de que el interés por la cultura italiana no dejara de aumentar entre los ciudadanos de la corona española y, por otra, de que el italiano, visto globalmente, fuera percibido a lo largo de las dos centurias siguientes como lengua de prestigio, como testimonia la edición del primer diccionario bilingüe: el Vocabulario de las dos lenguas toscana y castellana, de Cristóbal de las Casas, publicado en 1569 en Sevilla, según el modelo lexicográfico de Antonio de Nebrija (Diccionario latino-español [1492] y Vocabulario español-latino [ca. 1495]), en cuya introducción Cristóbal de las Casas hace hincapié en el conocimiento del italiano (2a). Al parecer, su éxito fue notable, ya que hasta 1622 tuvo doce ediciones.

Casi treinta años después, en 1596, sale a la luz la primera gramática de la lengua italiana para los españoles: L'arte muy curiosa por la cual se enseña muy de rayz, el entender y bablar la lengua italiana, de Francisco Trenado de Ayllón, según el modelo de la gramática de Nebrija (1492). Nótese que, en la aprobación de la imprenta, Luis de Salazar, en nombre del rey, califica el contenido de útil y necesario para los oficiales del reino. La extraordinaria estima del italiano entre los españoles se plasma en la queja en forma de carta del bachiller de Arcadia al Capitán Salazar, en la que critica el excesivo empleo de italianismos (2c), propugnando el empleo de voces patrimoniales. Incluso Juan de Valdés, conocido defensor de la lengua española hablada, califica la introducción de giros de origen italiano como adornos de la lengua ( $2 \mathrm{~d})$.

1 Por aquel entonces muchos españoles ilustres pasan por Bolonia y, a su vuelta, propagan un nuevo ideal de humanismo con las traducciones de obras italianas como La Divina Comedia, de Dante, llevada a cabo por Enrique de Villena (1427), o los cantos de Petrarca, por el Marqués de Santillana (Terlingen, 1943: 48), que posibilitaron la penetración de italianismos como soneto o novela (Lapesa, 1981: \$70). 
(2) a. cuyo conocimiento [del toscano] ha procurado, y procura tanta gente, que ya no ay hombre que no pretenda, ó dessee a lo menos aprenderla y cierto con muy gran razon porque de mas de la necesidad que ay, por el continuo trato con la gente italiana (Vocabulario de las dos lenguas, $4 \mathrm{~V}$ )

b. Francisco Trenado de Ayllón [...] que aviades compuesto un Arte muy copioso por el qual se enseña el entender, hablar, y pronunciar la lengua italiana, y atento a que era muy útil para los Vireyes, Embaxadores y otros ministros que imbiávamos a los negoscios y cosas tocantes a nuestro Real servicio, a los estados de Italia [...] (L'arte muy curiosa, p. 100)

c. ¿Para qué decís hostería, si on entenderán mejor mesón? ¿ Por qué estra$d a$ si es mejor y más claro camino? [...] ¿Para que foso si se puede mejor decir cava? [...] ¿Emboscadas y no celadas? [...] ¿Designo y no consideración? [...] Hable Vm la lengua de su tierra (Bachiller de Arcadia, carta al Capitán Salazar, 1547, apud Lapesa 1981: 409, la cursiva es original)

d. Vos tenéis razón, cuando de tal manera la sacase de sus quicios o quiciales, que el natural de mi lengua no me entendiese; pero, si me entiende tanto escribiendo megior como mejor, no me parece que es sacar de quicios mi lengua, antes adornarla con el ajena, mostrando que es tan general que, no solamente es entendida de los naturales, pero aun de los extraños. (Valdés, Diálogo de la lengua)

Como hemos podido comprobar, la inserción de términos de origen italiano en el español renacentista y áureo gozó de gran popularidad, de manera que cabe suponer que la interferencia va más allá del léxico y afecta también a elementos sociopragmáticos, como los relativos a la cortesía, dado que implican el ideal de la época descrito por Castiglione, cuya obra, El cortesano, fue traducida al español en 1534 por Juan Boscán y tuvo gran impacto en la sociedad española. Su admiración — casi idolatría - por parte del grupo social más alto queda reflejada en manuales de buenos modales, enormemente populares en aquella época (Zieliński, 2015: 1163-1164) y muy útiles para propagar las nuevas formas de tratamiento.

\section{Las fórmulas de tratamiento}

Una vez presentado el contexto sociohistórico, podemos pasar al análisis de las fórmulas de tratamiento, entendiendo por ellas las expresiones que codifican algún tipo de relación interpersonal entre los participantes de un acto de habla. Por cuestiones metodológicas, hemos decidido dividirlas en dos grupos 
- cuantitativamente desiguales- según su incorporación en el código de la lengua española para comprobar el grado de la interferencia del italiano en el nivel pragmático, en conformidad con la premisa de Thomason (2003: 69193), según la cual a medida que aumenta el conocimiento de la lengua fuente por parte de los usuarios de la lengua receptora, se registrarán más interferencias no léxicas (shift-induced interference) $\mathrm{y}$, a la inversa, a menor conocimiento de la lengua fuente por parte de los usuarios de la receptora, más interferencias habrá. Así, en el \$2.1 analizamos posibles préstamos del italiano y en el $\$$ 2.2 los calcos.

\subsection{Préstamos}

Resulta escasa presencia de formas de tratamiento tomadas directamente del italiano. Encontramos dos: miser y madona ${ }^{2}$, presentes desde el siglo XIV y especializadas semánticamente en el lexicón iberroromance.

El tratamiento miser o miçer (< it. messer 'mi señor') desde su primera documentación presenta un uso restringido como honorífico propio de la corona de Aragón ( $3 \mathrm{a}-\mathrm{c})$. Covarrubias llega a compararlo con el empleo del proclítico español don, delimitando erróneamente su empleo a la zona del antiguo reino de Valencia (3d).

(3) a. fechas las letras, micer Jufre tomo comiat \& fuess ende en Flandres. Et quando fue en Flandres dauant el comte Baldoyn, et lo recibio con grant honor et le fizo grant careza. Et despues miçer Jufre faulo con el compte et ordeno con ell que uiniesse con el comte de Chanpanya en el passage et que huuiesse al dicho comte de Chanpanya por capitan general.(J. Fernández de Heredia, Juan, Crónica de Morea, ca. 1377)

b. Y enbiaron a miser Gerónimo Totavilla, con setecientos cavallos lijeros y otros mil peones, pagados por el dicho tiempo (A. Santa Cruz, Crónica de los Reyes Católicos, 1491-1516)

c. Fueron presos el marqués de Rotelín e miser Roberto Totenile, sobrino del cardenal de Ruán, y el capitán de la gran guardia de Francia, e monsiur de Saboya, capitán de los hombres de armas borgoñones, y un hijo de monsiur de Muy (Santa Cruz, A. Crónica de los Reyes Católicos, 1491-1516)

2 Terlingen (1943: 301) estudia también el tratamiento de señoroto 'señor italiano', que no hemos podido registrar en la búsqueda del CORDE. 
d. Y lo que en Castilla llamamos don, es en Francia monsieur y en Italia monsigor, y lo mesmo había de sinificar el mosén de Cataluña y el micer de Valencia, si estos títulos no se hubieran afectado a los clérigos el uno, y el otro a los letrados (Covarrubias 1611/2006: s.v. don)

Algo parecido se observa con el tratamiento de madona (< it. madonna 'mi señora'), que, aunque hoy está circunscrito al ámbito estrictamente religioso ( $m a-$ dona 'la Virgen María'), durante siglos se utilizó como honorífico (Terlingen, 1943: 301). En el Libro de buen amor (4a), su primera documentación, funciona como xenismo del que se sirve el autor para situar la acción en un ámbito extranjero (Bretaña, en concreto), de ahí el empleo de madona y de mon señer. Es importante notar que el término en cuestión ya le resultaba conocido y lo asociaba con formas extranjeras. Como honorífico nos lleva otra vez al dominio aragonés (4b) y, en último término, al italiano, como muestra Colón (4c).

(4) a. Dixo Don Pitas Pajas: "Madona, si vos plaz, mostratme la figura e aján buen solaz.

"Diz la muger: "Mon señer, vós mesmo la catat fey ý ardidamente todo lo que vollaz. (Juan Ruiz, Libro de buen amor, 1330-1343)

b. El qual rey fizo mucha honor al emperador et caso una su fiia que se clamaua madona Caterina con Filipo, fillo del emperador Baldoyn (Juan Fernández de Heredia, Crónica de Morea, ca. 1377)

c. Sus Altezas me prometieron de me dar todo lo que me perteneçe y de poner en posesión de todo a Don Diego, como veiréis. Al señor miçer Juan Luis y a la señora madona Catalina escrivo. La carta va con esta (Cristóbal Colón, Carta a Nicolò Orderigo, 1502)

Los dos préstamos analizados demuestran que su integración en iberorromance se llevó a cabo a través del aragonés, en contacto con modalidades lingüísticas de Italia con la dominación del reino de Sicilia en 1282 por Pedro III el Grande. Una vez consolidados ahí, se extienden su empleo a otras zonas de la península.

\subsection{Calcos}

Si bien los dos préstamos hallados y analizados en la sección anterior pertenecen a la primera fase del contacto lingüístico, las formas de tratamiento que consideramos calcos se documentan posteriormente, en el siglo $\mathrm{XV}$, cuando 
las relaciones bilaterales han alcanzado su cima. En este grupo de fórmulas de tratamiento hallamos, por una parte, una serie de honoríficos como vuestra señoría (5a), vuestra excelencia ( $5 \mathrm{~b}$ ) y formaciones con el sufijo superlativo -ísimo ( $5 \mathrm{c}$ ), y por otra, la expresión de cercanía pragmática caro patrón (5e) (Terlingen, 1943: 299):

(5) a. Ya ve, señor, vuestra señoría, cómo ninguno vos socorre desde tan grand rato como ha que esperáys ser socorrido (Anónimo, Crónica de Don Álvaro de Luna, ca. 1453)

b. A VUESTRA GRANT excellencia humilmente supplica la Uniuersidat de la vuestra ciudat de Çaragoça. Que como cerqua las ordinaciones fechas sobre el nuevo regimiento de la dita Ciudat por el señor Rey D. Fernando de gloriosa memoria padre vuestro. haya menester algunas cosas en aquellas seyer mudadas anyadidas tiradas (Anónimo, Modificaciones y corroboraciones de las Ordenanzas de Zaragoza, ca. 1429)

c. Assi que, muy ilustrissimo Rey e Senor, no solamente es necessario e abasta a todo principe o senor ser abundado de todas las cosas ya dichas, mas estas otras muy nobles son mas honestas e conviuientes con las quales la vida e honor se aumenta e conserua (Torre, Cartas, ca.1456)

d. Bon chorno, caro patrón [...] No sé qué han dicho de horno (S. Rodríguez de Villaciosa, La vida bolgona. Entremés, 1657)

Aunque todas sirven para crear una imagen positiva del destinatario, recalcando una de sus cualidades, la interferencia del italiano se refleja en cada una de ellas de manera diferente.

Dentro del grupo de los honoríficos ${ }^{3}$, vuestra señoría es el caso de calco léxicopragmático del italiano más evidente, ya que procede de vostra signoria, aunque Croce (1895: 43-52) califica la fórmula italiana de hispanismo. No obstante, el rastreo que hemos realizado en el OVI pone de manifiesto que se halla en textos italianos desde la primera mitad del siglo XIII (6a) con significados expresivo-valorativos, con los cuales el emisor pretende ubicar al destinatario en una posición social superior a la suya, creándole de esta manera la imagen positiva que desea tener. En la segunda mitad de la misma centuria funciona como honorífico plenamente lexicalizado (6b).

3 Por honoríficos entendemos las expresiones que codifican léxica o gramaticalmente la relación social entre los participantes de un acto de habla (vid. Haase 1994). 
A juzgar por los datos proporcionados por el CORDE, su traspaso al español se llevó a cabo por vía directa. La hallamos por primera vez plenamente lexicalizada y como honorífico incuestionable en autores que, por su biografía, sabemos que pasaron una temporada en Italia. Entre ellos podemos mencionar a Juan de Mena (6c), quien viajó a Florencia con el cardenal de Torquemada en 1443, o Fernando del Pulgar, embajador del Reino de Castilla en Roma (6d).

A partir de finales del siglo XV fue incrementando su frecuencia de empleo (Zieliński, 2017) una vez adaptada satisfactoriamente a los gustos ceremoniales de la sociedad española de entonces, sin que los hablantes perdieran conciencia de su procedencia lingüística (6e-f). El honorífico en español se somete a restricción pragmática, en el sentido de que carece de extensión social (Ly 1981: 64), llegando a codificar tan solo el poder del referente: el propio de la clase social más alta $(6 \mathrm{~g})$, que, como vimos en el apartado anterior, tuvo contacto con la cultura italiana.

(6) a. segundo che la vostra signoria vedere potrà (Faba, Parlamenti in volgare, ca. $1243, O V I$ )

b. tant'èpotente- vostra signoria, c'avendo male più v'amo ogno dia, però tuttorla tropp'asicuranza (da Lentini, Rime, ca. 1250, OVI)

c. Bien así yo, muy poderoso Rey, uso en aqueste don y presente, ca estas flores que a vuestra señoría aparejo presentar (Mena, Homero roman$z a d 0,1442$ )

d. Estas variedades, muy poderoso señor, dan causa justa de sospecha que estos caualleros no vienen a vuestra señoría con zelo de vuestro seruicio, ni ménos con deseo desta justiçia que publican (Pulgar, Crónica de los Reyes Católicos, ca. 1484)

e. El buen Antonio habla bien, porque me trata al modo de Italia, donde en lugar de merced dicen señoría (Cervantes, Los trabajos de Persiles y Segismunda, 1616)

f. Merced es una cortesía usada particularmente en España, como en Italia la señoría, que es común a cualquier hombre honrado (Covarrubias, 1611/2006: s.v. merced)

Si bien vuestra señoría es una creación pragmática estrictamente italiana, en otras expresiones honoríficas como vuestra excelencia y las que utilizan el sufijo -ísimo, el influjo italiano fue crucial para el proceso de idiomatización de las respectivas fórmulas latinas. Aunque ambas se remontan a los inicios del 
feudalismo $(7 \mathrm{a}-\mathrm{b})$ y se caracterizan por focalizar cualidades intrínsecamente asociadas con la imagen básica de un destinatario de alta cuna, su repentina integración en el sistema de honoríficos del español de finales del cuatrocientos ha de relacionarse con la rica documentación diplomática, perteneciente al género epistolar, entre la corona aragonesa y los súbditos italianos ( $7 \mathrm{c}-\mathrm{d})$.

(7) a. serenissimus et christianissimus imperator(Gregorius Magnus, Registrum epistularum, 8, 10, ca. s. VII, BREPOLIS)

['serenísimo y cristianísimo emperador']

b. Vnde iterum quaesumus ut excellentia uestra in talium se causarum defensionenon misceat (Gregorio Magno, Registrum epistolorum, 4, 140, BREPOLIS)

c. E sea Serenissimo Rey, etc. Data en la villa de Madrit, a XXVIIII de enero del anyomil CCCCLXXXIII. Yo el rey. L. Gonçales, Secretarius Dirigitur serenissimo Ferdinando regi Sicilie, citra Farum (Anónimo, Fernando al rey de Nápoles, 1483)

d. Serenissimo rey, nuestro muy caro e muy amado sobrino. Entendido hauemos que la barcha de Manoli, patroneada por Francisco Gambacurta, con banderas vuestras, estos passados dias, tomo en la mar sessenta y vna pieça de chamelotos e vna bala de alcatiffas de Pelegrino Orlandis (Anónimo, Fernando al rey Fernando de Nápoles, 1495)

e. E ahunque esto sea auantage de la dicha majestat, visto que los dichos Sanctangeles tienen arrendado las dichas salinas, han de bistraer los dichos gastos, e hauer el trabajo todo de la dicha negociacion, vienen bien a ello por seruir a su excellencia, e porque han fallado en aquella cortesia y benefficio en el precio del dicho arrendamiento. (Anónimo, Capitulos entre don Fernando y Luis y Jaime de Santágel, 1484)

Estas siguen las pautas del ars dictaminis, desarrollado a finales del siglo XII, precisamente en Italia, con un objetivo preciso: la redacción de cartas diplomáticas latinas. (Bresslau, 1958: II: 252-53; Camargo, 1991: 22; Koch, 2008: 65). La expansión de la corona española no solo determina que se intensifique la correspondencia diplomática de una manera inusitada, sino también que se imponga el castellano en detrimento del latín. A la idiomatización de las fórmulas honoríficas latinas contribuyó, sin lugar a dudas, la interferencia del italiano, lengua en la que se registran ambas fórmulas plenamente lexicalizadas por lo menos desde el siglo XIV (8). 
(8) Per parte del Illustrissimo e excellentissimo segnor nostro (Anónimo, Grida viscontea dopo la vittoria di Borgoforte, 1398)

Et eo cum lui venissemo a li pedi de la vostra excelentia per mandare a complimento tuto desiderio (Matteo del Libri, Arringhe, ca. 1350)

En virtud de ello, si en la lengua fuente, el latín, y en la lengua de prestigio, el italiano, se atestiguan las mismas estructuras lingüísticamente cristalizadas, en la lengua receptora, el español, parece más que probable que la transferencia se llevara a cabo por repetición (Heine y Kuteva 2005: 73-5 y $92-5$ ) a partir de elementos conceptuales idénticos ${ }^{4}$. En este sentido, no solo opera el mecanismo del calco léxico (loan-translation) (Weinreich, 1963: 51), dada su incuestionable transparencia morfosintáctica, sino que también implica una transferencia conceptual (Zieliński, 2017:156-58.), de modo que las fórmulas españolas - creadas según el patrón latino y fuertemente favorecidas por el influjo italiano-codifican la posición más alta de la pirámide social feudal que ocupa el destinatario. Por consiguiente, igual que vuestra señoría, su empleo queda fuertemente limitado a los miembros de la clase social más elevada.

Por último, en cuanto al tratamiento de camaradería caro patrón (< it. caro patrone) (9a-b), creemos que ilustra, en realidad, un tipo híbrido (vid. Gómez Capuz, 2004: 53), en el sentido de que en su creación se aplicaron dos mecanismos: el préstamo y el calco. A este grupo Terlingen (1943: 299) agrega buen/ bon compañero como posible calco del italiano buon compagno 'hombre sociable'), pero su empleo ya se registra en el siglo XIII (9c).

(9) a. - En mala coyuntura y en peor sazón y en aciago día bajó vuestra merced, caro patrón mío, al otro mundo, y en mal punto se encontró con el señor Montesinos (Cervantes, Quijote, 1615)

b. JUE. ¿E vu a mi, caro patrón? (Lope de Vega, El peregrino en su patria, ca. 1604)

c. Çenus e Euménides, Meleager terçero, rencuravan a firmes el su buen compañero; (Anónimo, Libro de Alexandre, ca. 1250)

A juzgar por los datos proporcionados por el CORDE, el uso de caro patrón es esporádico, ya que se limita a contextos italianizantes de obras de las épocas renacentista y áurea.

4 Malkiel (1957: 1-7) lo califica de influjo catalítico. 
La pérdida del prestigio lingüístico del italiano a finales del siglo XVII llevó consigo la rápida desaparición de estas fórmulas de tratamiento.

\section{Conclusiones}

Como hemos podido observar, la influencia del italiano en español fue más allá del léxico o de la morfosintaxis e implicó, en gran medida, la creación de fórmulas de tratamiento que tuvieron éxito en el otoño de la Edad Media en la sociedad española, muy inclinada a la ceremonia y al rito.

El estudio también ha revelado que la integración de las fórmulas de tratamiento ajenas - préstamo - fue un proceso anterior a la adaptación de estructuras ajenas con elementos de la lengua española - calcos-. Independientemente del mecanismo aplicado, las fórmulas de tratamiento que atribuimos a la interferencia directa o indirecta del italiano se caracterizan por haber sufrido una rápida restricción semántico-pragmática, de modo que, una vez idiomatizadas en español, designan a un referente de la clase social alta fascinado por la cultura italiana.

Por último, la atracción de la clase social alta por lo italiano explica también por qué prevalecen las fórmulas de tratamiento que hemos analizado. Todas ellas marcan las relaciones socialmente desiguales entre los participantes de un acto de habla (uno de ellos procura mantener a toda costa su capital simbólico).

La única expresión de cercanía, caro patrón, fue propia de la época de la mayor influencia italiana y no superó la prueba del tiempo, ya que cayó en desuso con la pérdida del interés por la cultura y lengua de Petrarca a finales del siglo XVII.

\section{Bibliografía}

Ayala Simón, E. (2002): «Italianismos en DRAE 1992 (versión electrónica), heterogeneidad en las marcas del sector de las comidas». En: Domenico Antonio Cusato, Loretta Frattale (eds.), Atti del XX Convegno [AssociazioneIspanistiItaliani]. Missina: Andrea Lippolis, 37-50.

Bresslau, H. (1958): Handbucb der Urkundenlebre für Deutscbland und Italien. Vol. 2. Berlin: Walter de Gruyter.

BREPOLIS: Brepolis Publishers (online), Library of Latin texts: http://www. brepolis.net/index.html (04-2017).

Camargo, M. (1991): Ars dictaminis - ars dictandi. Typologie des sources du moyen âge occidental. Turnhout: Brepols. 
CORDE: Real Academia Española (online), Corpus diacrónico del español: http://www.rae.es (02-2017).

Covarrubias, S. ([1611] 2011): Tesoro de la lengua castellana o española (ed. Ignacio Arellano, Rafael Zafra). Madrid/Frankfurt am Main: Iberoamericana/ Vervuert.

Croce, B. (1895): La lingua spagnuola in Italia. Roma: E. Loescher.

Díez Borque, J. M. (1990): La vida española en el siglo de Oro según los extranjeros. Barcelona: Ediciones Serbal.

Dworkin, S. (2012): A History of the Spanish Lexicon: A Linguistic Perspective. Oxford: Oxford University Press.

Gómez Capuz, J. (2004): Préstamos del español: lengua y sociedad. Madrid: Arco/ Libros.

Haase, M. (1994): Respekt: Die Grammatikalisierung von Höflicbkeit. Múnich: Lincom Europa.

Heine, B., Kuteva, T. (2005): Language Contact and Grammatical Change. Cambridge NY: Cambridge University Press.

Hernández Alonso, C. (1996): «Ceremonial, cortesía y tratamientos en España a la llegada de los Borbones». Anuario de lingïística bispánica, 12, 85-100.

Koch, P. (2008): «Tradiciones discursivas y cambio lingüístico: el ejemplo del tratamiento "vuestra merced" en español». En: Johannes Kabatek (ed.), Sintaxishistórica del español y cambio lingüistico: Nuevas perspectivas desde las Tradiciones Discursivas. Madrid/Frankfurt am Main: Iberoamericana/ Vervuert, 53-88.

Lapesa, R. (1970) «Personas gramaticales y tratamientos en español». Homenaje a Menéndez Pidal, Revista de la Universidad de Madrid, 19, 4, 141-67.

Lapesa, R. (1981): Historia de la lengua española. Madrid: Gredos.

Líbano Zumalacárregui, A. (1991): «Morfología diacrónica del español: las fórmulas de tratamiento». Revista de filología española, 71, 1-2, 107-22.

Ly, N. (1981): La poétique de l'interlocution dans le théâtre de Lope de Vega. Bordeaux: Université de Bordeaux.

OVI: Istituto del Consiglio Nazionale delle Ricerche (online), L'Opera del Vocabolario Italiano: www.ovi.cnr.it (04-2017).

Pons Rodríguez, L. (2015), «La lengua del Cuatrocientos más allá de las Trescientas». En: José María García Martín (dir.), Teresa Bastardín Candón, Manuel Rivas Zancarrón (coords.), Actas del IX Congreso Internacional de 
Historia de la Lengua Española (Cádiz, 2012). Madrid/Frankfurt am Main: Iberoamericana/Vervuert, vol. 1, 393-430.

Sala, M. (1998): Lenguas en contacto. Madrid: Gredos.

Taavitsainen, I., Jucker, A. H. (eds.) (2003): Diachronic Perspectives on Address Term Systems. Amsterdam/Philadelphia: John Benjamins.

Terlingen, J. (1943): Los italianismos en español: desde la formación del idioma basta principios del siglo XVII. Amsterdam: NV Noord-Hollandsche Uitgevers Maatschappig.

Trenado de Ayllón, F. ([1596] 2016): Arte muy curiosa por la qual se enseña muy de rayz, el entender y bablar la lengua italiana (ed. Andrea Gualano). Firenze: Franco Cesati Editore.

Thomason, S. (2003): «Contact as a Source of Language Change». En: Brian D. Joseph, Richard D. Janda (eds.), The Handbook of Historical Linguistics. Oxford: Blackwell Publishing, 687-712.

Thomason, S. (2001): Language Contact. Edinburgh: Edinburgh University Press.

Weinreich, U. (1963): Languages in Contact: Findings and Problems. The Hague/ Paris: De Gruyter Mouton.

Zieliński, A. (2015): «"Hallé un río grandísimo, digo muy grande": historia y comportamiento del sufijo "-ísimo" en español». En: José María García Martín (dir.), Teresa Bastardín Candón, Manuel Rivas Zancarrón (coords.), Actas del IX Congreso Internacional de Historia de la Lengua Española (Cádiz, 2012). Madrid/Frankfurt am Main: Iberoamericana/ Vervuert, vol. 1, 1157-1170.

Zieliński, A. (2017): Las fórmulas bonorificas con el sufijo -ísimo en la bistoria del español. Contribución a la lexicalización de la deixis social. Frankfurt am Main: Peter Lang. 
Andrzej Zieliński

Jagiellonian University

\section{Italian influence on renaissance and golden age Spanish: the case of forms of address}

Key words: interference, borrowing, calque, Italian, Spanish, forms of address

As is well known, from the first half of the fifteenth century, the bilateral relations between Italy and Spain reached their climax with the conquest of the kingdom of Naples (1420). It is after this event in particular that many Spaniards imitate Italian speech, introducing many Italianisms, both lexical and morpho-syntactic. It may be assumed that the high prestige of Italian at that time also contributed to the adoption of Italian polite linguistic customs in Spanish, among which we find forms of address. The aim of the present paper is to analyse the interference of Italian in Renaissance and Golden Spanish in forms of address. Using the Corpus Diacrónico del Español (CORDE) we have sought to identify those formulas which shows either the direct or indirect influence of Italian. 
Andrzej Zieliński

Jagelonska univerza

\section{Interferenca italijanščine $\mathbf{v}$ španščini renesanse in zlatega veka. Ogovorne oblike}

Ključne besede: interferenca, izposojenka, kalk, italijanščina, španščina, ogovorne formule

Dobro je znano, da so bilateralni odnosi med Italijo in Španijo po zaslugi zavzetja Neapeljskega kraljestva (1420) v prvi polovici 15. stoletja dosegli vrhunec. Prav v tistem času je veliko Špancev začelo oponašati italijanski govor in pri tem $\mathrm{v}$ španščino vneslo veliko italijanizmov, tako na leksikalni kot na oblikovni in skladenjski ravni jezika. Domnevamo lahko, da je prestiž, ki ga je tedaj uživala italijanščina, vplival tudi na prevzemanje italijanskih vljudnostnih jezikovnih navad $\mathrm{v}$ španski jezik, med njimi tudi ogovornih formul. Prav zato je namen pričujočega članka analizirati interferenco italijanščine na ogovorne formule $\mathrm{v}$ španščini renesanse in zlatega veka. Avtor je $s$ pomočjo korpusa CORDE iskal tiste formule, na nastanek katerih je neposredno ali posredno vplivala italijanščina. 